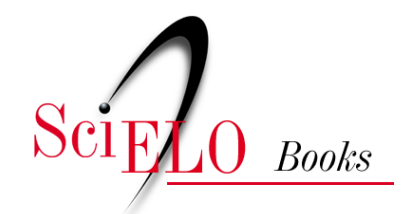

\title{
Sustentabilidade da produção energética no Rio de Janeiro as Pequenas Centrais Hidrelétricas $(\mathrm{PCH})$ potencializando regionalmente o território fluminense
}

\author{
Augusto César Pinheiro da Silva \\ Davi Schulman Miguens \\ Mônica Coelho Varejão
}

\section{SciELO Books / SciELO Livros / SciELO Libros}

SILVA, A.C.P., MIGUENS, D.S., and VAREJÃO, M.C. Sustentabilidade da produção energética no Rio de Janeiro: as Pequenas Centrais Hidrelétricas $(\mathrm{PCH})$ potencializando regionalmente o território fluminense. In: MARAFON, G.J., and RIBEIRO, M.A. orgs. Revisitando o território fluminense, VI [online]. Rio de Janeiro: EDUERJ, 2017, pp. 87-103. ISBN: 978-85-7511-457-5.

https://doi.org/10.7476/9788575114575.0006.

All the contents of this work, except where otherwise noted, is licensed under a Creative Commons Attribution 4.0 International license.

Todo o conteúdo deste trabalho, exceto quando houver ressalva, é publicado sob a licença Creative Commons Atribição $\underline{4.0}$.

Todo el contenido de esta obra, excepto donde se indique lo contrario, está bajo licencia de la licencia Creative Commons $\underline{\text { Reconocimento } 4.0 .}$. 


\title{
Sustentabilidade da produção energética no Rio de Janeiro: as Pequenas Centrais Hidrelétricas ( $\mathrm{PCH}$ ) potencializando regionalmente 0 território fluminense
}

\author{
Augusto César Pinheiro da Silval \\ Davi Schulman Miguens ${ }^{2}$ \\ Mônica Coelho Varejāo $0^{3}$
}

\section{Introdução}

0 planejamento e a gestão do território, a partir do recorte espacial "bacias hidrográficas", vêm ganhando força nas discussões acadêmicas desde o final do século XX. O entendimento dessas unidades espaciais é de fundamental relevância para o entendimento dos temas "preservação ambiental", "geração de energia" e "captação e distribuição de água", possibilitando que as bacias sejam identificadas como aquelas que podem modificar, se bem estudadas e apropriadas, os ritmos de escassez de água e, consequentemente, de energia, haja vista que a matriz elétrica brasileira é majoritariamente abastecida por hidroelétricas.

Em relação ao tema "produção energética", as bacias hidrográficas são os depositórios naturais de recursos renováveis (água), o que as torna focais para as políticas públicas nacionais de geração de hidroenergia, fonte ainda parcialmente potencializada no território nacional, apesar da enorme capacidade de produção de energia das bacias brasileiras.

Os padrões atuais de geração de energia no Brasil se baseiam em recursos renováveis (inclusive o grande aporte de água das Unidades Hidroelétricas de Energia [UHEs]), sendo a hidroenergia

\footnotetext{
1 Pós-doutor em Políticas Públicas pela Universidad Autónoma de Madrid e doutor em Geografia pela UFRJ. Professor do Programa de Pós-Graduação em Geografia da PUC-Rio e líder do grupo de pesquisa Gestão Territorial no Estado do Rio de Janeiro (GeTERJ). É bolsista Jovem Cientista Nosso Estado (JCNE), da Faperj.

2 Geógrafo pela PUC-Rio e mestre em Geologia pela UERJ. Trabalha com consultoria ambiental e energética.

3 Engenheira ambiental e sanitária pela PUC-Rio e especialista em Engenharia Sanitária pela UFRJ. Atualmente, é mestranda em Engenharia Ambiental pela UERJ.
} 
detentora da maior parcela de geração elétrica, com 70,6\% de representatividade do total gerado (EPE-BEN, 2014). Todavia, as UHEs causam grandes problemas socioambientais, deixando marcas espaciais expressivas (a remoção de ribeirinhos, que estimula o fluxo demográfico, a inundação de terras agrícolas, florestas e sítios arqueológicos, a formação de microclimas em áreas de barragens, entre outras) que são largamente estudadas por cientistas de diversas áreas, e que buscam alternativas para a geração de energia por meios menos impactantes.

Assim, outras formas de exploração dos recursos hídricos para a geração energética estão sendo ampliadas. Entre elas, destacam-se as Pequenas Centrais Hidrelétricas (PCH), cuja potência instalada é superior a $01 \mathrm{MW}$ e igual ou inferior a $30 \mathrm{MW} .{ }^{4}$ Tais estruturas produtivas potencializam o uso dos recursos nas bacias hidrográficas nacionais, pois apresentam baixo custo de construção e reduzido impacto ambiental durante a construção e a operação, em comparação às demais unidades geradoras.

Entre os fatores que tornam as PCH potenciais investimentos no Brasil, destaca-se a utilização de pequenos reservatórios, que, em relação às gigantescas obras necessárias para a construção de uma UHE, tornam menos complexas e barateiam as obras civis, em virtude do aproveitamento das quedas naturais dos rios. A união dos aspectos potenciais das $\mathrm{PCH}$ explicita seu caráter menos impactante nos âmbitos socioespacial, ecológico e econômico, encaixando-se, assim, no fornecimento de energia para centros urbanos e rurais menores, como se caracteriza a rede urbana fluminense. Ademais, a aplicação desse modelo de usinagem no estado do Rio de Janeiro está adequada aos aspectos hidroenergéticos, socioespaciais e físicos (geomorfológicos, hidrológicos, edáficos e climáticos) da unidade federativa em questão.

A pertinência desse artigo se ancora no crescimento da economia brasileira nas últimas duas décadas (1994-2014) e no Plano Decenal de Desenvolvimento da Energia (2014-2023), sendo as PCH uma forma de conter, ainda que parcialmente, as transformações nocivas que tal expansão tende a promover no espaço "em crescimento", como injustiça social e violência ambiental (eliminação de empregos, redução de mão de obra nos espaços de produção agrícola de pequeno porte, destruição de biomas ribeirinhos etc.), sendo que a opção pelas $\mathrm{PCH}$ pode trazer sustentabilidades diversas para as populações mais pobres e vantagens comparativamente mais amplas para os investidores públicos e privados no território fluminense. Diante disso, deve-se atentar para a atual abertura, em relação às instituições privadas, das condições de implantação de $\mathrm{PCH}$, o que pode ser observado em importantes bacias do estado do Rio de Janeiro e do Brasil.

A literatura utilizada para a elaboração deste artigo conta, entre outros autores, com Iglori (2001), Corò (2003), Castro [et al.] (2009) e Silva (2007, 2014), além de se recorrer a dados oficiais de órgãos e instituiçôes ligados a setores como a Agência Nacional de Energia Elétrica (ANEEL) e a Empresa de Pesquisa Energética (EPE).

\footnotetext{
4 Todavia, em 20 de janeiro de 2015, a presidente Dilma Rousseff sancionou a Lei no 13.097 , resultado do Projeto de Lei de Conversão (PLC) no 18/2014 sobre a Medida Provisória no 656/14, que, apesar de contar com alguns vetos, traz mudanças positivas para o setor elétrico, como, por exemplo, a ampliação do limite de potência das Centrais Geradoras Hidrelétricas (CGH) de $1 \mathrm{MW}$ para 3 MW.
} 


\section{A importância das Pequenas Centrais Hidrelétricas no setor elétrico nacional e no estado do Rio de Janeiro}

Conforme apontado por Gleick (1993), o Brasil apresenta uma das maiores reservas de água doce do mundo, em torno de $8 \%$, sendo parte desse total utilizado como carro-chefe para a geração de energia hidrelétrica. Soma-se a essa condição o aumento significativo do consumo de energia (e de água) no país, com a estabilização e o crescimento da economia, em muitas escalas, nas duas últimas décadas, o que impulsiona as esferas do planejamento e da gestão públicos a buscarem estratégias de geração de energia por múltiplas matrizes, frente às situaçôes conjunturais na sociedade brasileira na atualidade.

De acordo com Castro et al. (2009), por apresentar um expressivo parque gerador de energia hidráulica, o Brasil tem uma oferta de eletricidade competitiva e com reduzida emissão de gases do efeito estufa. Seguindo um movimento contrário em relação à boa parte dos países emergentes e centrais, ${ }^{5}$ os fatores favoráveis apontados desestimulariam políticas nacionais de fontes alternativas e renováveis; todavia, a legislação ambiental mais rígida e impositiva vigente no Brasil (frente aos enormes impactos socioambientais provenientes dos grandes empreendimentos hidrelétricos) ${ }^{6}$ faz com que tais fontes, como a bioeletricidade, a energia eólica e as PCH, ganhem espaço no cenário nacional. Ainda segundo Castro et al. (2009), "a expansão da capacidade instalada via usinas hidrelétricas terá como condição de base do sistema elétrico brasileiro uma contrapartida obrigatória e necessária, a complementação por outras fontes de energia” (p. 3). Por apresentar uma sazonalidade bem definida, as fontes alternativas atuariam complementando a carga nacional em períodos de seca.

No caso das fontes alternativas e renováveis e, especificamente, das PCH (que aumentou sua demanda, na segunda metade da primeira década do século XXI, entre 4\% e 5\% ao ano, EPE-BEN, 2014), as externalidades socioambientais positivas vão além de considerá-las uma fonte limpa, pois o uso de pequenos reservatórios (inferiores a $3 \mathrm{~km}^{2}$ ) diminui as possibilidades de desapropriação e de outros impactos associados às grandes barragens, com a utilização de quedas naturais e o modelo de engenharia "fio d'água"? Esse modelo, de acordo com a Figura 1, permite o uso de pequenos reservatórios que permanecem em níveis constantes, não havendo armazenamento para suprir o escoamento sazonal. Vale ressaltar

\footnotetext{
5 Hoje, o que se vê é o mundo, de modo geral, investindo e buscando fontes renováveis para a geração de energia, e o Brasil investindo no Pré-Sal (muito mais do que em qualquer fonte renovável). O próprio EPE-BEN (2014) aponta que o crescimento da oferta das fontes energéticas foi representado em $80 \%$ por petróleo, gás natural e derivados.

${ }^{6}$ Com a promulgação da Resolução Conama no 001/86 (23/01/1986), que estabeleceu as normas para a Avaliação de Impactos Ambientais, a implantação de empreendimentos de médio a grande porte está condicionada a um processo de licenciamento ambiental e a um Relatório de Impactos sobre o Meio Ambiente (EIA/RIMA).

7 Usinas hidrelétricas "a fio d'água" são aquelas que não dispōem de reservatório de água, ou o têm em dimensões menores do que poderiam ter. Optar pela construção de uma usina "a fio d'água" significa optar por não manter um estoque de água que poderia ser acumulado em uma barragem (Adaptado de Faria, 2011).
} 
que projetos recentes de UHE vêm adotando esse modelo, contemplando-se a estratégia de modernização de seus idealizadores: a de atender a legislação no que diz respeito aos impactos socioambientais.

Figura 1. Exemplo de modelo padrão de fio d' água da PCH Chave do Vaz, instalada no rio Negro, Cantagalo, RJ

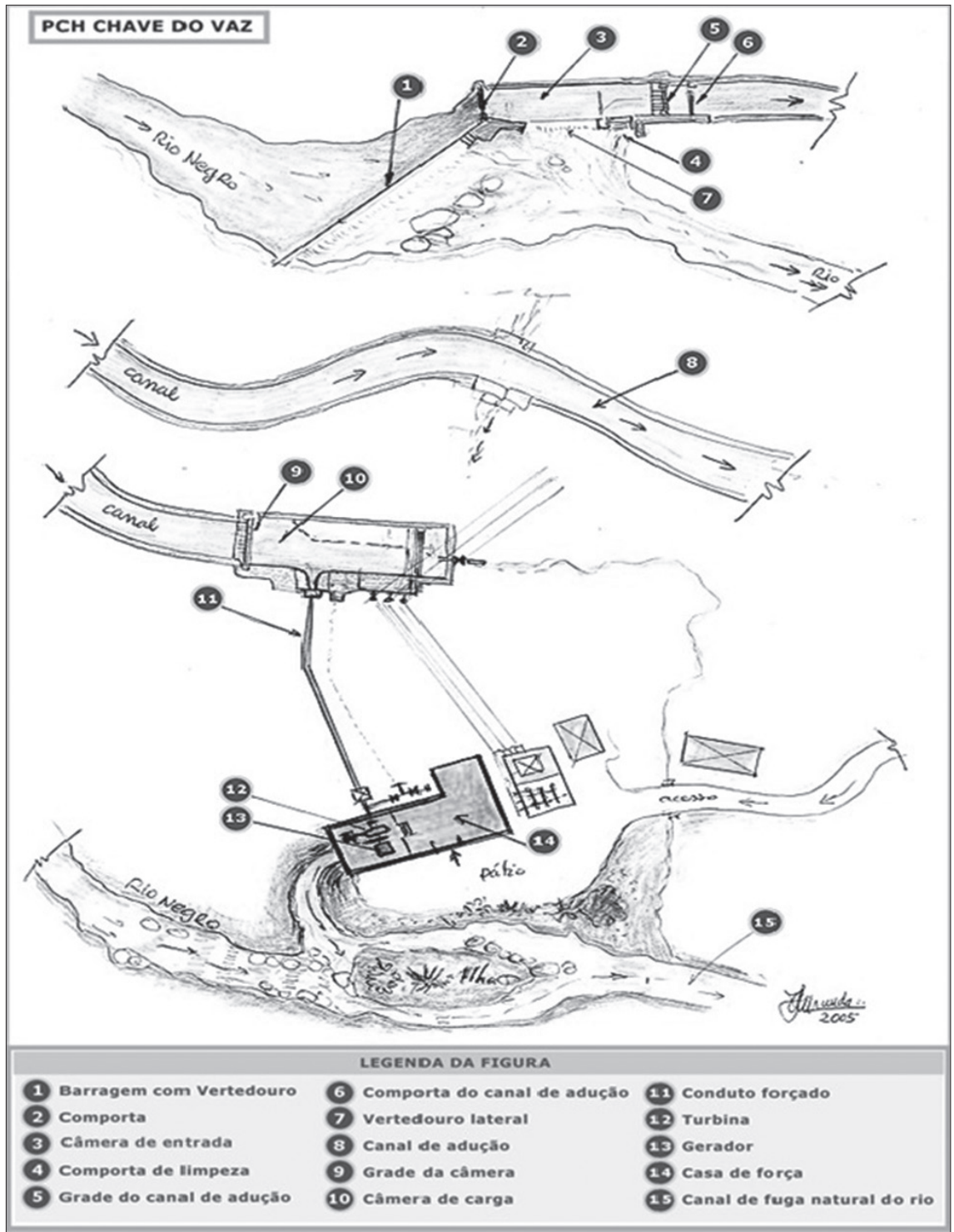

Fonte: Governo do Estado do Rio de Janeiro, 2007.

Outro atrativo das $\mathrm{PCH}$ é o menor tempo para sua construção, fato que permite a rápida expansão da geração de energia elétrica de maneira descentralizada. Essa característica permite que a energia gerada possa ser utilizada em escala local nos pontos em que não há ligação com a 
rede transmissora, diminuindo-se as perdas ao longo de seu transporte para outros espaços de consumo. Nesse sentido, competitivamente, as $\mathrm{PCH}$, assim como os projetos hídricos de forma genérica, são unidades de geração de energia que se caracterizam pelo capital intensivo, com reduzido custo marginal. Tal condição reforça a atratividade econômica de um empreendimento que apresenta vida útil longa. $\mathrm{O}$ esquema padrão de uma $\mathrm{PCH}$ pode ser visto na Figura 1 ( $\mathrm{PCH}$ Chave do Vaz, Cantagalo, Rio de Janeiro), para que se tenha a dimensão espacial do empreendimento, assim como a dos elementos que a compõem e fazem funcionar.

Com relação à sua limitada capacidade de geração de energia, as $\mathrm{PCH}$ apresentam maior adequação para ofertar sua produção em um Ambiente de Contratação Livre (ACL), mais conhecido como Mercado Livre. O ACL envolve diferentes agentes do setor elétrico, como geradores, consumidores livres, comercializadores e importadores/exportadores, segmentos do mercado no qual se realizam as operações de compra e venda de energia elétrica, a partir de contratos bilaterais livremente negociados, conforme regras e procedimentos de comercialização específicos (EPE-BEN, 2014).

\subsection{Panorama atual das $P C H$ na matriz elétrica nacional}

Com um potencial hidráulico inventariado em cerca de $260 \mathrm{GW}$, o Brasil ainda possui $60 \%$ de seu potencial a ser explorado, sendo que apenas um terço de sua capacidade total está em operação ou construção (Castro et al., 2009). Segundo o Balanço Energético Nacional de 2014, que apresenta dados relativos ao ano base de 2013 (Gráfico 1), a capacidade instalada da fonte hidrelétrica para 2013 foi de $86 \mathrm{GW}$. A potencialidade do setor já é um dos pontos centrais das políticas públicas de energia do país, sendo que o parque gerador vem apresentando ritmo constante em sua expansão, como, por exemplo, de 2012 para 2013 a capacidade instalada da fonte hidrelétrica cresceu 2\% (EPE-BEN, 2014). Entretanto, aumentaram os problemas referentes ao consumo exponencial de energia, concomitantemente à escassez de água nos reservatórios do país, nos últimos cinco anos - com agravamentos ampliados entre 2013 e 2015 -, o que afeta o abastecimento doméstico e industrial de água nos grandes centros metropolitanos do país e os custos da energia elétrica, em múltiplas escalas de produção e consumo. 
Gráfico 1. Evolução decenal da composição das fontes geradoras de energia elétrica no Brasil (\%)

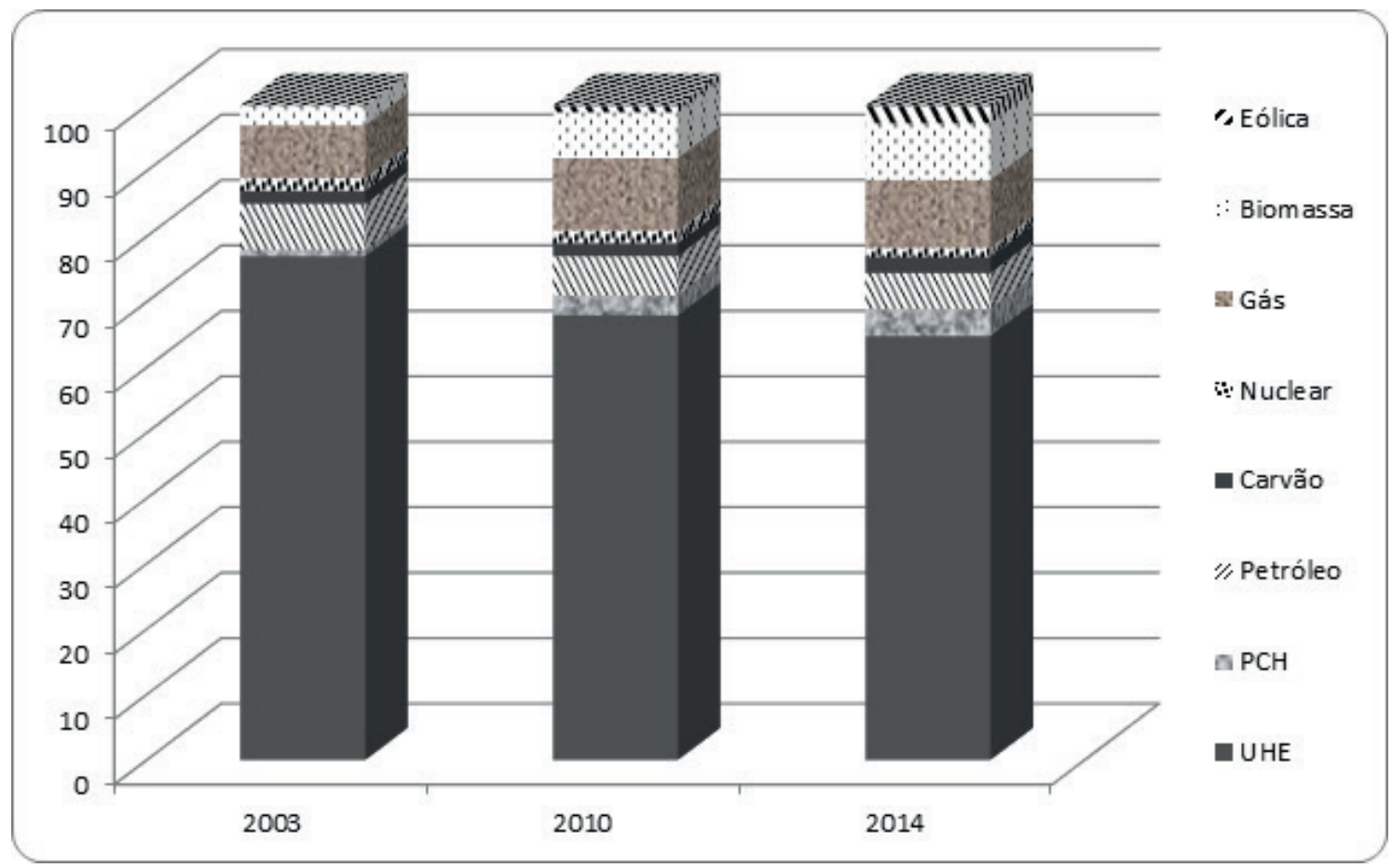

Fontes: EPE-BEN, 2014; ANEEL, 2014.

Vale destacar o aumento da participação das fontes alternativas e renováveis no período compreendido entre 2003 e 2014. Conforme o Gráfico 1, em 2003 apenas 4\% da composição total de energia do país vinha desses tipos de fonte. Já em 2010, esse número aumentou para 11\%, com merecido destaque para a biomassa, e em 2014 subiu para mais de $15 \%{ }^{8}$

De acordo com o Banco de Informaçôes de Geração (BIG) da ANEEL, o Brasil, em 2014, apresentava 463 empreendimentos do tipo PCH em operação, totalizando 4,6 GW de potência instalada. Em escala nacional, esse valor era equivalente a 4,08\% do total do parque gerador de energia elétrica naquele ano. Vale ressaltar ainda que, em maio de 2014, existiam 176 empreendimentos em fase de construção (30) e outorgados (146), o que equivaleria a 2,326 MW a serem acrescidos ao parque gerador nacional (BIG-ANEEL, 2015).

Segundo o Plano Decenal de Expansão de Energia 2023 da EPE, a expansão da fonte PCH já contratada e em construção, com previsão de entrada em operação comercial para os anos de 2014

\footnotetext{
${ }^{8}$ Apesar da clara tendência de aumento da geração de energia por métodos alternativos e renováveis no país, as estatísticas da EPE-PDE $(2019,2010)$ estimam o total de empreendimentos hidrelétricos viabilizados até 2019 em mais 40 UHE.
} 
a 2018, é apresentada conforme Tabela 1. Cabe ressaltar que o acréscimo da potência instalada para cada ano, disposta nessa tabela, refere-se à capacidade contratada nos leilóes de energia de reserva.

Tabela 1. Expansão da PCH contratada de 2014 a 2018

\begin{tabular}{|l|l|c|c|c|c|c|}
\hline Tipo & Região & $\mathbf{2 0 1 4}$ & $\mathbf{2 0 1 5}$ & $\mathbf{2 0 1 6}$ & $\mathbf{2 0 1 7}$ & $\mathbf{2 0 1 8}$ \\
\hline \multirow{5}{*}{ PCH } & \multicolumn{7}{|l|}{ Potência (MW) } & Sudeste/Centro-Oeste & 169 & 71 & 0 & 0 & 286 \\
\cline { 2 - 7 } & Sul & 40 & 30 & 18 & 0 & 113 \\
\cline { 2 - 7 } & Nordeste & 0 & 0 & 0 & 0 & 6 \\
\cline { 2 - 7 } & Norte & 21 & 32 & 12 & 3 & 0 \\
\hline \multirow{2}{*}{ Total } & $\mathbf{2 3 0}$ & $\mathbf{1 3 3}$ & $\mathbf{3 0}$ & $\mathbf{3}$ & $\mathbf{4 0 5}$ \\
\hline
\end{tabular}

Fonte: Adaptado do PDE 2023, 2014.

Em relação à distribuição das $\mathrm{PCH}$ pelo território nacional, as unidades federadas das macrorregiōes Sudeste e Sul do país apresentam maior concentração de empreendimentos (323 PCHs) e maior capacidade instalada (28,4 GW). O estado de Minas Gerais é o carro-chefe nacional desse tipo de empreendimento, por apresentar a maior potência em megawatts (742 MW ou 7,42 GW) e um total de PCH 4,2 vezes maior do que o do total do estado do Rio de Janeiro - 97 PCH mineiras contra apenas 23 delas no território fluminense (BIG-ANEEL, 2013).

Para os próximos anos, o parque gerador de energia nacional continuará a ser consideravelmente diversificado. Vale destacar que essa diversificação possibilitará o crescimento das fontes renováveis, reforçando-se o caráter "limpo" das políticas ambientais no país, como preveem os planos diretores e as políticas interescalares das instâncias de gestão pública do federalismo brasileiro, que ampliaram o poder das esferas locais na geração de recursos sustentáveis para o desenvolvimento nacional (Silva, 2014). Até 2023, 42,5\% da oferta interna de energia será renovável, sendo a maior parte proveniente de derivados de cana-de-açúcar e de energia hidráulica (EPE-PDE 2023, 2014).

Sob essa perspectiva, até 2023 as PCH acrescerão à sua potência instalada mais 2,01 GW. Vale destacar o aumento da participação da energia eólica no parque gerador para os próximos anos, tendo em vista que o potencial estimado para essa fonte gira em torno de $22,44 \mathrm{GW}$, equivalente a $75 \%$ do mercado atual de energia elétrica para as fontes de energia eólica, biomassa, solar e as próprias $\mathrm{PCH}$ (PDE 2023, 2014). 
Diante dessa potencial capacidade de expansão das fontes renováveis, cabe destacar como se comportarão as $\mathrm{PCH}$ no contexto analítico em foco, além de compreender como tal investimento tem condições de potencializar ainda mais o estado do Rio de Janeiro para os investimentos presentes e futuros.

\subsection{Panorama do setor hidrelétrico no estado do Rio de Janeiro: potencialidades}

A macrorregião Sudeste é a maior consumidora de energia elétrica do país, necessitando de aproximadamente $34 \%$ de toda a produção nacional para suprir sua carga (EPE-BEN, 2014). Como é a maior produtora, a malha dos serviços de transmissão é bastante complexa, o que torna a macrorregião (que ainda é a mais industrializada e povoada do país) uma fonte de pesquisas necessárias para que sejam identificadas as potencialidades dos projetos de desenvolvimento local/estadual/regional baseadas em fontes renováveis e alternativas, como, por exemplo, a PCH.

Das quatro unidades federadas da macrorregião, o estado do Rio de Janeiro apresenta-se como um dos maiores produtores de energia elétrica do país, apesar de suas reduzidas dimensões territoriais em relação às outras unidades. Mesmo sendo um importante produtor no conjunto dos estados brasileiros, o Rio de Janeiro não produz energia suficiente para suprir a carga estadual de consumo, o que o torna, portanto, um importador de energia elétrica (EPE-PDE 2023, 2014).

Atualmente, o estado do Rio de Janeiro apresenta 8,7 GW de potência instalada, dos quais $86 \%$ são usinas termelétricas (nucleares e de gás e óleo). O total de $\mathrm{PCH}$ em operação no estado é de 23 empreendimentos, somando $305 \mathrm{MW}$ de potência. De acordo com o relatório de acompanhamento da expansão da oferta de geração de energia elétrica das PCH, o qual fornece informações acerca das usinas já outorgadas e em fase de implantação, o estado do Rio de Janeiro apresenta, nessa situação, cinco usinas: uma se encontra em estágio de obra paralisada, duas em andamento e duas não iniciadas. No Gráfico 2, observa-se a importância das PCH no estado em relação à sua situação por operação, à quantidade de empreendimentos e à respectiva potência.

É importante destacar o potencial apresentado pelo território fluminense para ser explorado. As PCH em projeto básico representam um total de 19 empreendimentos que somam 206 $\mathrm{MW}$, sendo que 18 já tiveram seus projetos básicos elaborados e um apresenta projeto básico em fase de elaboração. Cinco usinas ainda não entraram em operação comercial e se encontram outorgadas, sendo que três delas apresentam problemas com a licença ambiental. Também é grande o número de pequenos empreendimentos no estado que se enquadram como CGH e estão desativados. São mais de cinquenta empreendimentos que, juntos, apresentam uma potência superior a $15 \mathrm{MW}$. Da mesma forma que as $\mathrm{PCH}$, essas CGH podem elevar substancialmente sua potência a partir de estudos que ampliem a perspectiva de sua vazão e da altura de sua queda (ANEEL, 2015). 


\section{Sustentabilidade da produção energética no Rio de Janeiro}

Figura 2. Distribuição da população carioca, metropolitana e total no estado do Rio de Janeiro: superpovoamento relativo na Região Metropolitana do Rio de Janeiro (RMRJ).

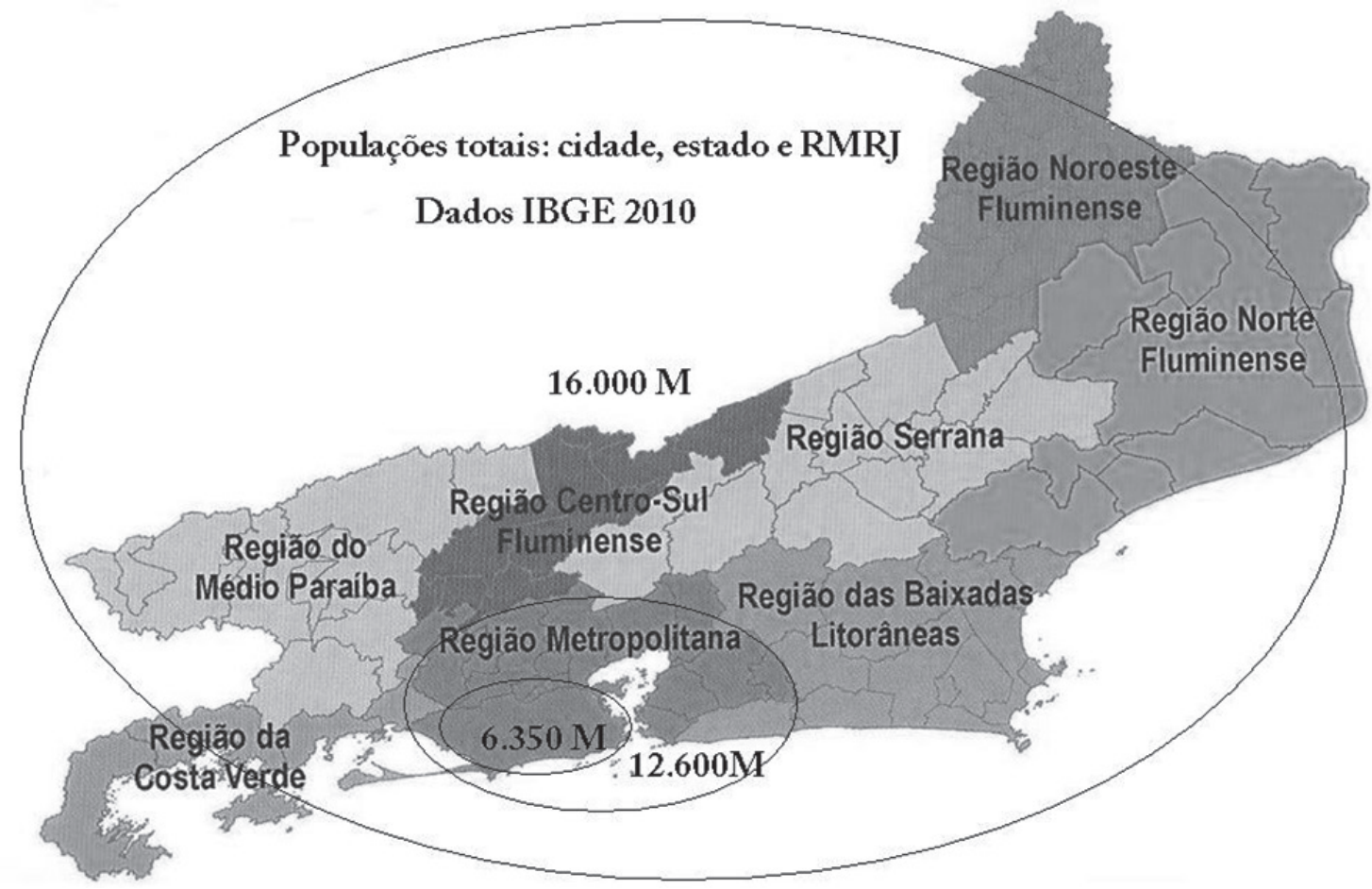

Fonte: Adaptado de Ceperj, 2013, e IBGE, 2010.

Levando-se em consideração tal potencial de investimentos em PCH no estado, é certo que podem favorecer a manutenção e/ou atração de população para as várias regiōes do estado subpovoadas em relação à sua área core, a megarregião metropolitana do Rio de Janeiro (Figura 2). Frente à grande concentração demográfica de população fluminense na faixa metropolitana da cidade carioca (quase $80 \%$ da população total do estado na RMRJ), os investimentos em PCH poderiam tornar as outras sete regiōes de governo, além da metropolitana, capazes de agregar empreendimentos médios e/ou pequenos que alavancassem negócios específicos, diferenciados e pautados nas potencialidades regionais não metropolitanas. As PCH se apresentariam como pequenos grandes investimentos dos setores público e privado, os quais estimulariam negócios diversos e novas fontes de arrecadação de impostos pelos poderes municipais.

A maior parcela do potencial das bacias hidrográficas do estado do Rio de Janeiro, no que diz respeito à capacidade hidráulica, encontra-se em inventário ou projeto básico, sendo que as bacias potencializáveis estão situadas em regiões montanhosas do estado (na faixa de altitude que varia dos trezentos aos oitocentos metros), locais em que é possível utilizar as variações altimétricas na concepção das PCH. 
Deve-se destacar que os rios Macaé e Negro (bacia do Rio Dois Rios) estão com seus inventários em fase de análise pela ANEEL (2013), fato que representa um futuro complemento ao potencial atualmente apresentado. Outro ponto que merece menção é o fato de que os inventários realizados até o presente momento levam em consideração os principais rios da rede de drenagem das bacias do estado. Isso faz com que rios de menor expressão não sejam contemplados nesses estudos, mantendo-se seus potenciais desconhecidos.

Tais dados permitem avaliar a atual organização dos investimentos produtivos no território do estado do Rio de Janeiro. O grande potencial em PCH inventariado seria um importante dinamizador da Região Serrana, possibilitando o direcionamento dos capitais industriais e agrícolas, assim como o fortalecimento dos serviços urbanos, tanto para a referida região como para seu entorno. Isso se observa pelos grandes aportes de investimentos industriais e de serviços nas regióes Metropolitana e das Baixadas Litorâneas, no litoral central do estado. Esses investimentos industriais e logísticos vêm causando grandes transformações na dinâmica territorial fluminense.

De acordo com Coró (2003), deve-se considerar que uma base tecnológica instalada possibilita novas redes sociais, produtivas e geográficas. Portanto, o gerenciamento desses novos vínculos entre as infraestruturas logísticas, capital privado e seus territórios cria um enorme desafio para os gestores locais, em que falhas no planejamento e na gestão produzirão profundas externalidades negativas, tendo a população e o território como principais vítimas.

O grande potencial em PCH inventariado no estado do Rio de Janeiro, principalmente na Região Serrana, pode ser entendido como elemento catalisador da modernização socioespacial em curso no território fluminense desde meados dos anos 1990. Silva (2007) reforça a perspectiva de potencialização não materializada como uma possibilidade para estímulos materiais, humanos e políticos nos espaços com demanda reprimida. A aplicação desses estímulos de maneira correta por agentes de gestão e sua apropriação pelos atores locais resultariam no desenvolvimento de potencialidades espaciais que abririam caminho para a sustentabilidade socioespacial, que estaria baseada em múltiplas visões e perspectivas, para além da visão técnico-produtiva dos territórios. Essas possibilidades serão examinadas a seguir. 


\section{As PCH como potencialidades para o desenvolvimento local: algumas reflexões iniciais sobre sua gestão}

Figura 3: Faixa no território fluminense com grande concentração de PCH.

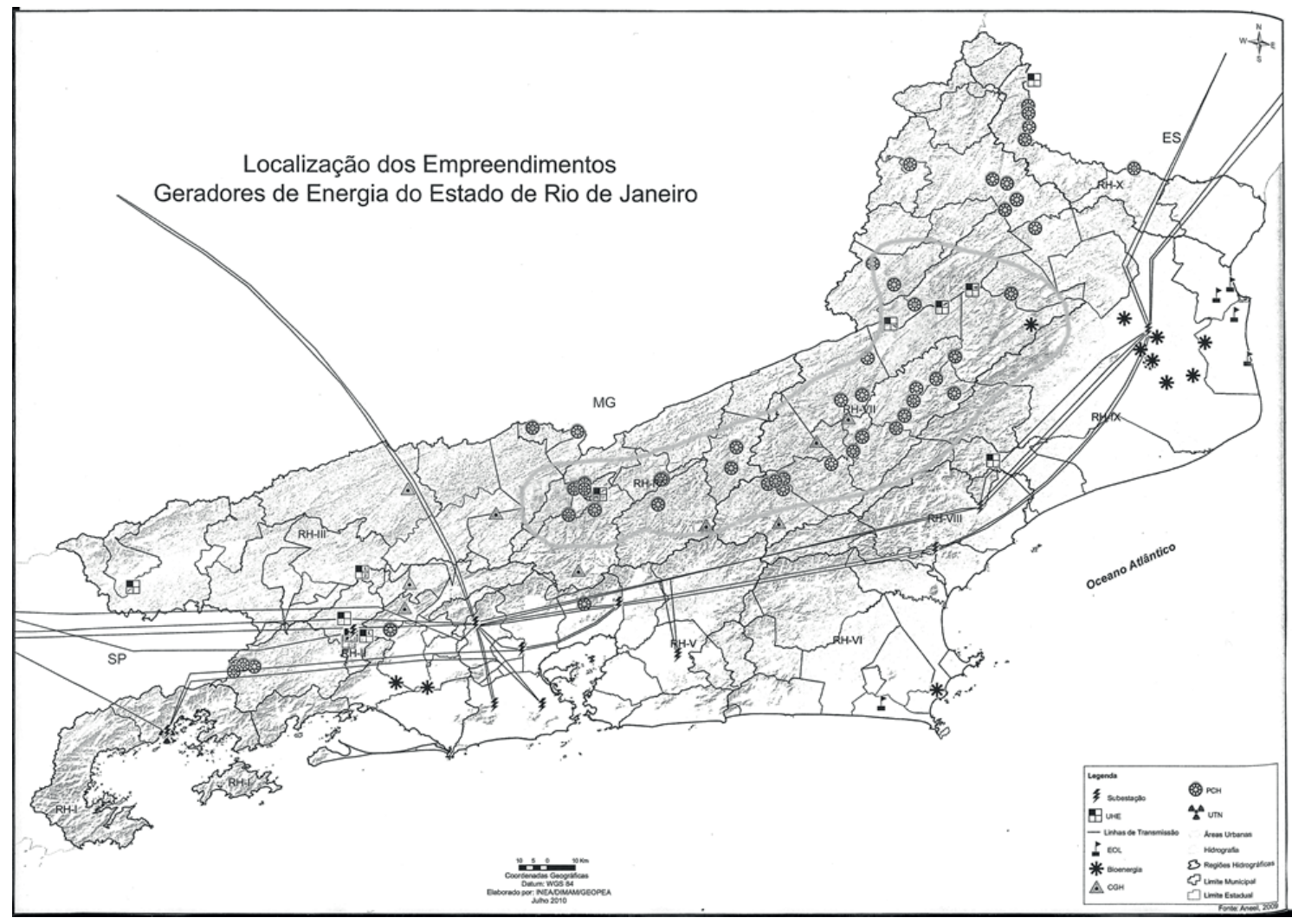

Fonte: Adaptado de SEA/INEA, 2010.

Considerado um setor de base na economia, a geração de energia hidrelétrica no Brasil deve ser profundamente discutida e questionada, notadamente o modelo $\mathrm{PCH}$, pelo fato de poder ser realizado pelas esferas do poder federativo de menor abrangência territorial (estados e municípios), o que o tornará um manancial de formas e estratégias de planejamento e gestão sobre desenvolvimentos sustentáveis e oportunos. Com a implantação das $\mathrm{PCH}$ como projetos de sustentabilidade local, surgirão possibilidades de melhorias socioeconômicas e ambientais em relação a padrões ecológicos diversos. De acordo com Somekh e Campos (2002), essa condição incrementaria os quadros produtivos locais pela diversificação e a dinamização de economias, a partir da geração de emprego e renda. Para atingir a esfera social, deve-se considerar a inclusão de diferentes setores, notadamente aqueles ligados à economia popular, como a pequena produção agrícola, a agroindústria artesanal e o microcomércio de bairro, atividades que movimentam diversos produtos da cadeia produtiva. Além disso, vale lembrar que os programas 
socioambientais implementados para cumprimento da legislação ambiental, como hoje exigem os municípios submetidos a planos diretores e zoneamentos socioeconômicos e ecológicos, trarão benefícios para os meios social, físico e biótico das áreas de influência dos empreendimentos.

Todo empreendimento do tipo PCH possui fortes vínculos com o território e influi positiva e negativamente em seus meios ambientais constitutivos. As transformações geradas pela implantação de empreendimentos hidroenergéticos que afetam, direta e indiretamente, o meio ambiente, a população em seu modo de vida, a dinâmica de trabalho, os hábitos e costumes têm sido pauta constante nos fóruns da sociedade civil organizada e do Poder Público em seus diversos órgãos e escalas. Inevitavelmente, a gestão ineficaz das transformações e da relação com os atores estratégicos envolvidos gera passivos para o território e seus atores.

A falta de um conhecimento mais profundo acerca das variáveis envolvidas nessa dinâmica usualmente contribui para que sejam criados planos parciais e/ou paliativos e, consequentemente, ações pouco eficazes. O direcionamento incorreto ou ineficiente de recursos para a efetiva solução das transformações pode aumentar, de modo significativo, os gastos inicialmente previstos para a implantação de um empreendimento, seja ele hidroenergético ou de qualquer outra natureza.

Como identificado por diversos relatórios oficiais da ANEEL, a dinamicidade do parque gerador hidrelétrico nacional causou um movimento de constante reformulação da legislação ambiental. Atualmente, diversos empreendimentos estão sujeitos ao licenciamento ambiental, e as PCH estão inseridas nesse grupo. E, para que elas alcancem a fase de operação, devem cumprir uma série de exigências provenientes das agências reguladoras de setores dos órgãos ambientais responsáveis. Portanto, a seguir, abordam-se as principais atribuiçôes das empresas para atingirem as licenças ambientais.

Os estudos ambientais provenientes de exigências dos órgãos ambientais podem ser vistos como instrumentos que podem ser utilizados com diversas finalidades. Com a promulgação da Resolução Conama no 001/1986, a elaboração do Estudo de Impacto Ambiental/Relatório de Impactos sobre o Meio Ambiente (EIA/RIMA) passou a ser uma exigência em boa parte dos empreendimentos hidrelétricos para obtenção da licença prévia, representando benefícios em diversos aspectos. Além disso, levam-se em conta as características de engenharia para que seja possível propor medidas mitigadoras e compensatórias diante das externalidades sempre presentes. Vale lembrar que o conteúdo do EIA/ RIMA está em consonância com o termo de referência dos órgãos ambientais responsáveis. Outro aspecto importante é o caráter público do RIMA, o que dá à população interessada acesso às informaçóes do empreendimento, bem como a possibilidade de participação ativa nas audiências públicas realizadas para aprovação do processo de licenciamento ambiental.

Mais um importante instrumento de avaliação para o licenciamento ambiental de empreendimentos hidrelétricos é o Relatório Ambiental Simplificado (RAS), referente à Resolução Conama no 279/2001. Como o RAS surgiu em um período de crise energética nacional e abertura para o investimento do capital privado em PCH, o instrumento contempla os mesmos aspectos do EIA, mas de maneira simplificada, a fim de agilizar o processo de licenciamento. Vale lembrar que esse estudo de avaliação ambiental é voltado somente aos empreendimentos causadores de baixo impacto.

Além dos estudos citados, chama-se a atenção também para o Plano Básico Ambiental (PBA). Segundo a Resolução Conama no . 06/1987, o PBA é o estudo desenvolvido para o cumprimento das condicionantes, com vistas à obtenção da licença de instalação de uma PCH. Esse documento apre- 
senta todas as medidas de controle e os programas socioambientais propostos no EIA, possibilitando a definição das açôes e dos programas a serem desenvolvidos em todas as etapas do projeto, desde o início das obras até a etapa de operação do empreendimento e seu monitoramento.

Para que seja possível um melhor entendimento da aplicabilidade desses instrumentos na gestão pública, foi realizada uma visita às obras de instalação da $\mathrm{PCH}$ Santo Antônio, no rio Grande, ${ }^{9}$ município de Bom Jardim, bacia do rio Dois Rios, Rio de Janeiro. Assim, a partir de entrevista realizada com uma analista ambiental da empresa, foi possível ter acesso ao PBA da PCH Santo Antônio e obter informaçôes sobre os outros empreendimentos nesse mesmo rio.

Figura 4: Localização das PCH visitadas em trabalho de campo (outubro de 2013).

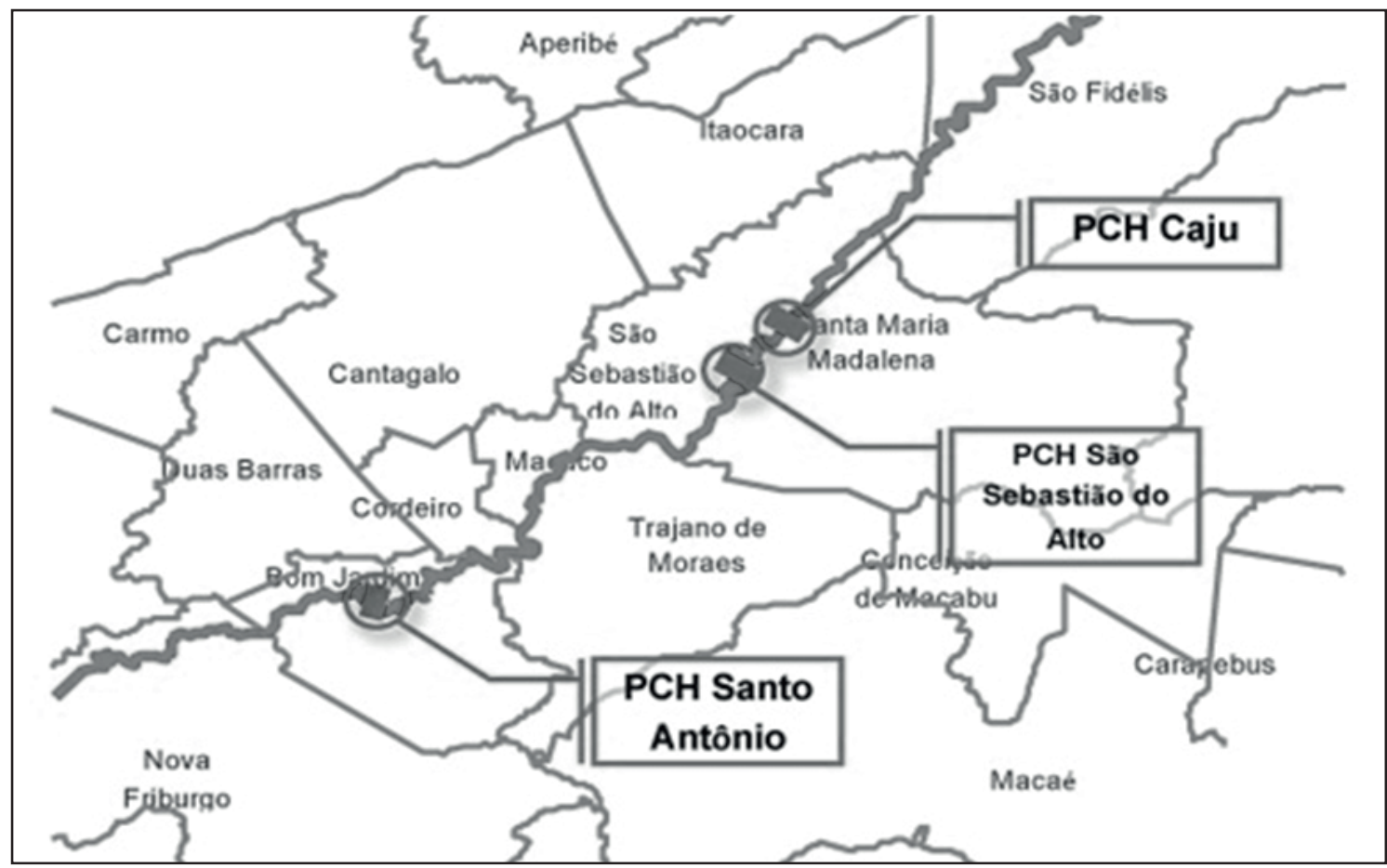

Fonte: Disponível em http://www.grupoenergisa.com.br/Geracao/usinasemconstrucao/pchsriogrande.aspx. Acesso em 7 out. 2013 (adaptado).

Dessa forma, foi possível identificar os programas de cunho socioambiental, seus objetivos e os respectivos resultados para as áreas direta ou indiretamente afetadas pela $\mathrm{PCH}$ :

a. Programa de Gestão Ambiental: promover os programas ambientais de maneira articulada, atender aos requisitos legais e exigências técnicas do órgão ambiental e funcionar como ouvidoria para a população;

\footnotetext{
9 A PCH visitada é a terceira da empresa Energisa Geração Rio Grande S.A (pertence ao grupo Energisa S.A.), a qual também é proprietária das PCH São Sebastião do Alto e PCH Caju, todas alocadas no rio Grande.
} 
b. Programa Ambiental de Construção: estabelecer critérios e requisitos para orientar os construtores em relação ao cuidado com as questôes ambientais no período de construção;

c. Programa de Contratação e Desmobilização de Mão de Obra: priorizar a contratação de mão de obra local (Bom Jardim) para internalizar os efeitos positivos da geração de empregos relacionados ao empreendimento;

d. Programa de Comunicação Social: constituir canais de diálogo entre empreendedor e sociedade, principalmente para a população diretamente afetada pelo empreendimento, de forma a motivar sua participação nas diferentes etapas de implantação;

e. Programa de Educação Ambiental: desenvolver ações educativas formuladas em processo participativo, visando capacitar/habilitar os setores sociais para a efetiva melhoria da qualidade ambiental e de vida na região.

f. Programa de Apoio às Unidades de Conservação: aplicar 0,5\% do custo do empreendimento em Unidades de Conservação na área de influência da $\mathrm{PCH}$;

g. Programa de Indenização de Terras e Benfeitorias: recompor o patrimônio e a economia dos proprietários de terras afetadas, de acordo com as condiçóes encontradas;

h. Programa de Remanejamento da População: garantir que o processo de remanejamento da população atingida ocorra em consonância com as expectativas e demandas dos atingidos, preservando sua qualidade de vida;

i. Programa sobre Patrimônio Cultural: proteger os bens culturais ameaçados de destruição pelo empreendimento;

j. Programa de Monitoramento das Comunidades Aquáticas: complementar o inventário da ictiofauna do rio Grande e reestruturar as comunidades de peixes na área de influência da PCH;

k. Programa de Gerenciamento de Resíduos e Efluentes: monitorar a qualidade da água antes e depois da construção, promovendo medidas para controlar e equilibrar as comunidades faunísticas e aquáticas na área de influência da $\mathrm{PCH}$;

1. Programa de Limpeza da Bacia de Acumulação: mensurar e retirar toda a vegetação da área a ser inundada;

m. Programa de Reflorestamento das Margens do Reservatório: promover a recomposição e a manutenção das matas ciliares do rio Grande;

n. Programa de Controle de Processos Erosivos: mapear e conter os processos erosivos a montante e a jusante do empreendimento a partir do reflorestamento com espécies nativas;

o. Programa de Hidrossedimentologia: monitorar o comportamento hidrossedimentológico antes e depois do enchimento do reservatório.

(Entrevista e consulta realizadas em 18 de outubro de 2013) 


\section{Sustentabilidade da produção energética no Rio de Janeiro}

Ainda de acordo com a entrevistada, as outras duas $\mathrm{PCH}$ receberam os mesmos programas citados, o que possibilitou a obtenção da Licença de Operação pelo INEA. A partir da figura anterior, constata-se a abrangência da atuação da empresa, na bacia do Rio Grande, atingindo os municípios de Bom Jardim, Santa Maria Madalena e São Sebastião do Alto. Os programas dos três empreendimentos são voltados aos meios físico, biótico e social, e estão correlacionados entre si. Devido ao elevado número de programas, destacam-se os resultados mais expressivos obtidos na PCH Santo Antônio.

Inicialmente, cabe destacar o programa de reflorestamento das margens do rio dentro da área de influência do empreendimento. Para a implantação dessa PCH, foi necessária a supressão de 20 hectares de florestas. Em contrapartida, realizou-se o reflorestamento de 300 hectares com mudas nativas provenientes de viveiro construído no local, e parte das mudas virá de sementes catadas das espécies nativas, evitando-se a mudança da carga genética do local. Dessa forma, foram reflorestadas áreas degradadas e improdutivas no entorno do empreendimento, do rio e entre fragmentos florestais, fato que possibilita a formação de corredores ecológicos. Assim, uma nova via foi criada para que houvesse maior fluxo gênico entre as espécies animais e vegetais.

O reflorestamento foi correlacionado com as medidas do programa de controle de processos erosivos, levando-se em conta que a reconstituição da cobertura vegetal trará benefícios, como a minimização de processos intempéricos, erosivos e, consequentemente, de assoreamento do rio Grande. Além disso, o programa de apoio às Unidades de Conservação (UC) vem permitindo investimentos em UC já existentes ou na criação de novas UC (o grupo econômico já criou duas UC classificadas como Reservas Particulares do Patrimônio Natural em dois empreendimentos no estado de Minas Gerais). De acordo com o PBA e a entrevistada, o programa de educação ambiental está em desenvolvimento nas instalações da PCH, na rede de ensino público e na comunidade local. Esse programa busca disseminar novas posturas, hábitos e costumes junto à comunidade de Bom Jardim e, para isso, foi realizada a capacitação de agentes multiplicadores da rede pública de ensino municipal e estadual, bem como da secretaria de saúde do município, para a realização de palestras, oficinas, videodebates e alguns eventos, como o plantio de mudas nativas e oficinas para conhecimento da fauna, da flora e dos recursos naturais da região. Além disso, atividades relacionadas à gestão de resíduos e saneamento básico para diminuir a incidência de doenças de veiculação hídrica estão sendo desenvolvidas nas mesmas oficinas.

O programa de comunicação social apresenta-se como uma ferramenta de aproximação dos três setores produtivos do município de Bom Jardim. Com esse programa, todos os impactos positivos e negativos são comunicados com o intuito de criar um relacionamento construtivo entre o grupo e a sociedade civil, o que faz com que o primeiro passe a ser reconhecido pelo segundo como um novo agente local e regional, com responsabilidades junto aos vizinhos e ao território no qual está alocado.

Para finalizar, vale destacar que a contratação de $95 \%$ da mão de obra da construção foi proveniente do município de Bom Jardim, atingindo mais de trezentos funcionários no pico da obra (2012). Acrescenta-se que a prefeitura do município passou a receber impostos como ISS e ICMS da PCH Santo Antônio.

Com os exemplos citados, percebe-se que as medidas adotadas para fins de licenciamento ambiental são permanentes, pois vão perdurar após o início da operação das PCH. A interrupção dos programas contidos no PBA pode acarretar a não renovação da licença de operação das $\mathrm{PCH}$. 
Portanto, constata-se que o cumprimento dos dispositivos legais do processo de licenciamento ambiental apresenta caráter positivo para o território. O primeiro fator que comprova esse fato é a possibilidade de acesso da população aos estudos desenvolvidos pelo empreendedor, disponibilizando um conteúdo pouco conhecido e enriquecedor para a população local, como, por exemplo, a composição de fauna, flora e elementos naturais de seu território. Outro fator importante é a inclusão da população na política socioambiental da empresa, por meio dos programas do PBA, mostrando uma nova perspectiva, que passa pela consideração dos moradores como interlocutores diretos no território. Além disso, esses estudos podem ser utilizados como subsídios para políticas públicas e estudos de futuros projetos, uma vez que identificam as potencialidades e as vulnerabilidades locais e regionais.

\section{Referências}

BIG-ANEEL - Agência Nacional de Energia Elétrica. Relatórios diversos. Disponível em: http://www. aneel.gov.br. Acesso em: 20 abr. 2015.

BRASIL. Lei no 9.433, de 20 de dezembro de 1997. "Institui a Política Nacional de Recursos Hídricos, cria o Sistema Nacional de Gerenciamento de Recursos Hídricos, regulamenta o inciso XIX do art. 21 da Constituição Federal, e altera o art. $1^{\circ}$ da Lei no 8.001, de 13 de março de 1990, que modificou a Lei no 7.990, de 28 de dezembro de 1989”. Disponível em: http://www.planalto.gov. br/ccivil_03/Leis/L9433.htm.

CASTRO, Nivalde de et al. "A importância das fontes alternativas e renováveis na evolução da matriz elétrica brasileira”, V Seminário de Geração e Desenvolvimento Sustentável, Fundación Mapfre, 2009.

CEPERJ. Mapa das regióes de governo do estado do Rio de Janeiro, 2014. Disponível em: http://www. ceperj.rj.gov.br/ceep/info_territorios/Reg\%20Gov_2013.pdf. Acesso em: 15 mar. 2016.

CORÒ, Giancarlo. "Logística, economia global e desafios para o Made in Italy". In MONIÉ, Fréderic e SILVA, Gerardo (orgs.). A mobilização produtiva dos territórios: instituições e logística do desenvolvimento local. Rio de Janeiro: DP\&A, 2003.

EPE-BEN - Empresa de Pesquisa Energética. Relatórios diversos. Disponível em: http://www.epe.gov. br. Acesso em: 20 abr. 2015.

FARIA, Ivan Dutra. "Ambiente e energia: crença e ciência no licenciamento ambiental, Parte III. Núcleo de Estudos e Pesquisa do Senado Federal". Texto para Discussão no 93. 2011. Disponível em: http://www.senado.gov.br/senado/conleg/textos_discussao/TD99-IvanDutraFaria.pdf. Acesso em: $1^{\circ}$ maio 2015.

FIORI, José Luís. Em busca do dissenso perdido: ensaios críticos sobre a festejada crise do estado. Rio de Janeiro: Insight, 1995.

GLEICK, P. H. Water in crisis: a guide to the world's fresh water resources. S.l.: Editor Book, 1993. $473 \mathrm{p}$.

IBGE - Instituto Brasileiro de Geografia e Estatística. Dados do Censo Demográfico de 2010. Disponível em: www.ibge.gov.br. Acesso: 14 mar. 2016. 


\section{Sustentabilidade da produção energética no Rio de Janeiro}

IGLIORI, Danilo Camargo. Economia de clusters industriais e desenvolvimento. São Paulo: Iglu/Fapesp, 2001.

MME - Ministério do Meio Ambiente. Plano Decenal de Energia (PDE, vários anos). Relatórios diversos. Disponível em: www.mme.gov.br. Acesso em: 20 abr. 2015.

SANTOS JÚNIOR, Orlando Alves dos. Democracia e governo local: dilemas da reforma municipal no Brasil (tese). UFRJ/IPPUR, 2000.

SEA - Secretaria Estadual do Ambiente e INEA - Instituto Estadual do Ambiente. O estado do ambiente: indicadores ambientais do Rio de Janeiro 2010. Rio de Janeiro: Secretaria do Ambiente/Governo do Estado do Rio de Janeiro/SEA/INEA, 2011. 160 p.

SILVA, Augusto César Pinheiro da. "Discursos e práticas institucionais no estado do Rio de Janeiro: paradoxos organizacionais na modernização do espaço rural fluminense”. In OLIVEIRA, Rogério et al. (orgs.). Paisagem, espaço e sustentabilidades: uma perspectiva multidimensional da geografia. Rio de Janeiro: PUC-Rio, 2007. 330 p.

—_ "Geografia e meio ambiente: as políticas de estado na configuração de sustentabilidades no Brasil”, Revista eletrônica ACTA Geográfica, Boa Vista, "Geografia Política e Geopolítica”, 2014, pp. 121-37. Disponível em: http://revista.ufrr.br/index.php/actageo/article/view/2355/1347.

SOMEKH, Nadia e CAMPOS, Candido M. A cidade que não pode parar: planos urbanisticos de São Paulo no século XX. São Paulo: Mackpesquisa, 2002. 